\title{
La actividad en las redes sociales: Un estudio de caso en la industria del fitness The activity on social networks: A case study in the fitness industry \\ Jerónimo García-Fernández*, Jesús Fernández-Gavira*, Joaquín Durán-Muñoz**, Luisa Vélez-Colón*** \\ *Universidad de Sevilla (España), ${ }^{* *}$ Bodysolution (España), ${ }^{* * *}$ West Virginia University (USA)
}

Resumen. La necesidad de interactuar con los clientes en las organizaciones deportivas, hace que el objetivo de este trabajo sea describir cómo las cadenas de fitness en España gestionan sus contenidos en las redes sociales y qué repercusión tienen sobre los clientes. Enmarcada en la metodología cuantitativa, se presenta un estudio de caso sobre una muestra de siete cadenas de centros de fitness cuya suma total son 73 instalaciones deportivas. El análisis descriptivo mostró en relación a Facebook, que los contenidos de multimedia, información específica e imagen de marca eran los más publicados por las cadenas coincidiendo con el mayor número de Me Gusta, Compartir y Comentarios. También horarios e información general obtuvieron valores altos en Compartir. En relación a Twitter, la imagen de marca obtuvo el mayor número de post al igual que fue el contenido con mayor número de Menciones, Retweets y Favoritos, aunque también destacó atención al cliente en Menciones, e información específica en Retweets y Favoritos.

Palabras Clave. Facebook, Twitter, centros deportivos, industria del fitness, clientes.

Abstract. The need to interact with customers in sports organizations drives the purpose of this manuscript, to describe how fitness chains in Spain manage their content on social networks and its impact on consumers. Using quantitative methodology, seven different fitness center chains, also known as franchises, were sampled. The seven fitness franchises totaled 73 sports facilities. A descriptive analysis showed multimedia content; specific information and brand image had the most publications on Facebook by franchises coinciding with the greatest number of Likes, Share and Comments. Scheduling and general information obtained high number of Share. When analyzing content on Twitter, brand image had the largest number of posts as well as Mentions, Retweets and Favorites. Customer service also demonstrated a higher number of Mentions and specific information in Retweets and Favorites.

Keywords. Facebook, Twitter, fitness centres, fitness industry, customers.

\section{Introducción}

Como muestran diferentes estudios, las redes sociales son hoy en día un medio de comunicación muy activo. Así, el 87\% de las personas de entre 15 y 24 años en Australia las usan de manera cotidiana (Australian Bureau of Statistics, ABS, 2011), en Estados Unidos el 73\% de los usuarios de internet recurren a ellas (Pew Research Center, 2013), o en España más de 14 millones de personas de entre 18 y 24 años las utilizan como medio de comunicación (Asociación para la Investigación en Medios de Comunicación, AIMC, 2014). A su vez, según el estudio del Observatorio Nacional de Telecomunicaciones y de la SI (2011), las redes sociales más utilizadas en España son Facebook, Messenger, YouTube y Tuenti, observándose por ejemplo que el $81 \%$ de las mujeres y el $75 \%$ de hombres tienen cuenta de Facebook. De igual modo es destacable que las personas de entre 18 y 24 años son los que más utilizan las redes sociales con una frecuencia diaria del $80 \%$ frente al $49 \%$ de las de 45 a 54 años. En este sentido, no solo las personas hacen uso de esta herramienta de comunicación sino que las empresas utilizan en gran medida las redes sociales para comunicarse con sus clientes, donde Facebook es la más utilizada (Asociación Española de la Economía Digital, ADIGITAL, 2014). Así, las razones principales por las que las empresas las utilicen son para encontrar nuevos clientes, mejorar la satisfacción, incrementar sus ventas e ingresos, fidelizarlos $y$, construir una buena reputación en torno a la imagen de la marca (He, Zha \& Li, 2013). Por ello, las redes sociales son el escenario perfecto para entablar relaciones con los consumidores favoreciendo la fidelización del cliente (Brodie, Hollebeek, Juric' \& Ilic', 2011; Brodie, Ilic', Juric' \& Hollebeek, 2013; Yoshida, Gordon, Nakazawa \& Biscaia, 2014) a partir de crear una idea positiva sobre la organización o empresa en cuestión.

Concretamente y al igual que la mayoría de empresas y organizaciones de todos los sectores, las organizaciones deportivas están percibiendo los beneficios de las redes sociales y están buscando maneras eficaces de utilizarlas como parte de su marketing global, para la comunicación con usuarios y para ges-

Fecha recepción: 22-09-14- Fecha envío revisores: 25-09-14- Fecha de aceptación: 24-02-15 Jerónimo García-Fernández jeronimo@us.es tionar las estrategias de marca (Coyle, 2010; Filo, Lock \& Karg, en prensa). En esta línea Williams y Chinn (2010) ilustraron las ventajas de las redes sociales para entidades deportivas, en particular en lo que respecta a la promoción y las fuertes relaciones con los consumidores del deporte, señalando la importancia de las redes sociales para alcanzar los objetivos relacionales con los clientes. Igualmente, las ventajas que las redes sociales aportan a las empresas deportivas también son descritas por Abreza, O’Reilly y Reid (2013) contribuyendo a un mayor conocimiento de los consumidores, una mayor interacción con los mismos, una adherencia más efectiva y una eficiencia en el uso de los recursos. Otros autores que apoyan esta tesitura son Pedersen (2013) y Gantz (2013) que destacaron los retos de equilibrar los beneficios y oportunidades de las redes sociales con los medios tradicionales de comunicación.

En este sentido, autores como Pronschinske, Groza y Walker (2012) encontraron que la interacción con los fans a través de la herramienta del Facebook podía repercutir positivamente en el número de fans o Me Gusta de una marca. En esta línea Hopkins (2013) concluyó que las redes sociales permitían a las diferentes marcas comunicarse con sus usuarios de diferentes maneras donde Twitter lo hacía en tiempo real mediante tweets y Facebook permitía además utilizar otros medios interactivos como compartir vídeos o imágenes, que permitían a los usuarios y empresa compartir material de manera enriquecedora para ambos. Por esta razón, se podría afirmar que en la actualidad las redes sociales son un medio para conseguir objetivos de mejoras de marketing y para interactuar con los usuarios. Sin embargo, los estudios relacionados con las redes sociales en el sector deportivo han estado encaminados mayormente al análisis de los espectadores de eventos deportivos o fans de clubes deportivos, existiendo un vacío en el sector del fitness y por lo tanto una oportunidad en su investigación.

\section{Contexto de estudio: la industria del fitness}

Según establece la International Health, Racquet \& Sportsclub Association (IHRSA), la industria del fitness sigue creciendo a nivel mundial (IHRSA, 2012). En esta línea, García, Lera-López y Suárez (2011) afirman que el sector privado de organizaciones de fitness está en auge, llegando a convertirse en el líder del sector de las instalaciones de ocio (Datamonitor, 2010). En concreto, Europa es según la IHRSA (2012) el merca- 
do más rentable en la actualidad coincidiendo con un aumento en el número de practicantes. De entre los tres países con mayor facturación y número de clientes, se encuentra España con más de siete millones de practicantes y con una facturación de más de 3000 millones de euros anuales, situándole entre los primeros países a nivel mundial en facturación y en número de clientes. Asimismo, Sacavém y Correia (2009) consideran a España como el segundo en el ratio de penetración del sector (15.3\%), observándose en el aumento del número de instalaciones, y en un mayor crecimiento de los que pertenecen a un centro de fitness (García Ferrando \& Llopis, 2011).

A su vez Guedes, Maças y Serrasqueiro (2013) afirman que el sector se caracteriza porque los centros de fitness son jóvenes y en general suelen ser Pymes por lo que tienen las características comunes de este tipo de organización, es decir están constituidas por menos de 250 personas y el volumen de negocios anual no excede los 50 millones de euros. No obstante, hay que tener presente que en una industria en la que la mayoría son Pymes con un bajo número de empleados, es importante analizar las organizaciones de referencia para poder extrapolar los datos a un contexto en general. Por esta razón, el análisis de las cadenas resulta interesante ya que detrás de su gestión, suelen existir departamentos específicos dependiendo de los factores que se analicen, y por tanto las redes sociales suelen gestionarlas profesionales de las mismas.

En este sentido, aun siendo una de las industrias con mayor incremento de practicantes (European Commission, 2014), la investigación sobre gestión y marketing ha estado orientada a aspectos diferentes de las redes sociales (García-Fernández, Bernal-García, Fernández-Gavira \& Vélez-Colón, 2014). Justamente, existen trabajos que tienen por objetivo conocer las dimensiones de la calidad y la satisfacción (Afthinos, Theodorakis \& Nassis, 2005; García, Cepeda \& Martin, 2012; Morales, Hernández-Mendo \& Blanco, 2009), el valor percibido (Nuviala, Pérez-Ordás, Boceta, Grao-Cruces, Nuviala \& González, 2012), el análisis de las mejores escalas para medir la satisfacción (Martínez \& Martínez, 2010), el estudio de la fidelización mediante programas de actividad física (García \& Pires, 2010), la segmentación de clientes (Rial, Alonso, Rial, Picón \& Varela, 2009) o cómo influye la conveniencia de servicio en la satisfacción y ésta en las intenciones futuras de comportamiento (Chang \& Jay, 2012). Sin embargo, existe un déficit de trabajos relacionados con la utilización de las redes sociales entre usuarios de centros de fitness, aun siendo una tendencia en alza (Özsoy, 2011) a la que hay que prestar atención y que da sentido a la presente investigación. Concretamente, las redes sociales como Facebook o Twitter aglutinan a millones de personas contribuyendo a difundir una variedad de contenidos entre diferentes tipologías de usuarios, convirtiéndolas en la perfecta plataforma para divulgar información relacionada con las organizaciones a través de la participación activa de los usuarios (Aguado \& García, 2009).

Por esta razón, este estudio trata de responder las preguntas de ¿cuáles son los patrones que se pueden encontrar en los sitios de Facebook en centros de fitness?, ¿cuáles son los patrones que se pueden encontrar en los perfiles de Twitter en centros de fitness?, y ¿cuáles son las principales diferencias entre ambas redes sociales? En esta línea, la presente investigación tiene como objetivo describir cómo las cadenas de la industria del fitness en España llevan a cabo sus actividades en las redes sociales y la repercusión que estas tienen sobre los usuarios.

\section{Material y métodos}

\section{Muestra}

Este trabajo analizó siete grandes cadenas de centros de fitness cuyo número total de instalaciones sumaron 73 centros de fitness, examinando las redes sociales Facebook y Twitter, y analizando los contenidos que incorporan sus fans a los respectivos perfiles de cada cadena. Las cadenas analizadas se eligieron por ser organizaciones de referencia en el sector. Por mantener la confidencialidad de las empresas, a cada una se le asignó las iniciales CD (cadena de centros de fitness) y la numeración del 1 al 7.

La elección de estas cadenas fue en primer lugar porque todas ellas tenían perfiles de Facebook y de Twitter. Igualmente, era necesario que todas tuvieran más de dos instalaciones y que dentro de su web apareciera su intención de seguir creciendo en número de centros de fitness. De ellas, cinco cadenas eran nacionales y dos locales, situándose geográficamente alguna de las 73 instalaciones en 15 comunidades autónomas de España. Concretamente no existía ninguna instalación de las cadenas analizadas en Aragón ni en Navarra.

\section{Instrumento}

Según Aggarwal, Gopal, Sankaranarayanan y Singh (2012), los contenidos que aportan los usuarios en las redes sociales se han considerado importantes en los estudios de redes sociales. Por esta razón se optó como instrumento de recogida de datos la hoja de observación. Para su elaboración se contó en primer lugar con dos profesores de Ciencias del Deporte de universidades españolas, una profesora de una universidad de Estados Unidos, un gerente de un centro de fitness y un gestor de contenidos de redes sociales (community manager). Tras cinco reuniones y con objeto de concluir cuáles podrían ser los contenidos publicados y en qué consistían en las redes sociales de centros de fitness, se seleccionaron nueve. No obstante, en una última reunión y con la inclusión de dos community managers más, se decidió la reducción a ocho módulos de contenidos resumiendo en un único contenido aquel relacionado con «imágenes» y «videos». Los módulos fueron: Multimedia, referente a aquellos recursos audiovisuales (imágenes y videos) que son reflejados en la página de Facebook o Twitter, ya sea por la propia empresa o por terceros. Horarios, hacía referencia a la información que emite la empresa sobre los horarios de clases dirigidas en sus instalaciones. Pese a que esta información suele aparecer en formato de imagen, pertenece a este módulo. Eventos, englobaba todos aquellos anuncios sobre la realización de un evento deportivo o concurso, dentro o fuera de las instalaciones. A este módulo solo pertenecen aquellos eventos o concursos que son organizados por la empresa. Promociones, se refería a todas aquellas acciones de marketing destinadas a la captación de clientes. Son mensajes de promoción aquellos que reflejen información sobre aperturas, precios y servicios, puntos de información y matriculación, etc. En el caso de Twitter, aquellos mensajes de otras personas u organizaciones retuiteados por la empresa sujeta a la medición que estén relacionados con la promoción del centro se engloba en este apartado. Información General, acoge los contenidos e información sobre noticias, eventos, curiosidades, etc. que no tienen ninguna relación con el ámbito de la actividad física y la salud. Información Específica, hacía mención a todos aquellos contenidos que pertenecen al ámbito de la actividad física y la salud: recomendaciones para hacer ejercicio, eventos deportivos, consejos para cuidar la salud, etc. Imagen de Marca, se refería a los mensajes utilizados por la organización para crear ambiente positivo en torno a su imagen: mensajes de bienvenida, de ánimo, de agradecimiento, de motivación, retweets de comentarios positivos, etc. Finalmente, Atención al Cliente, se refería a los mensajes que utiliza la organización para informar de las circunstancias en las que se encuentran las instalaciones, contestar preguntas y peticiones de usuarios.

La hoja de observación analizaba los contenidos de las páginas de Facebook y perfiles de Twitter de las organizaciones 
anteriormente mencionadas a través de la medición del número de Me Gusta y Seguidores, los contenidos publicados, la frecuencia de subida de contenidos y la respuesta que los usuarios ofrecían a través de Me Gusta, Comentarios y Compartir en Facebook, y Menciones, Retweet y Favoritos en Twitter. Así, cada red social tenía una hoja de observación donde se contabilizaban cada uno de los factores comentados. En la primera columna se indicaba el día de análisis, y en las sucesivas cada contenido con sus Me Gusta, Comentarios y Compartir en Facebook y Menciones, Retweet y Favoritos en el caso de Twitter. Cada fila pues, contaba la actividad diaria de las redes sociales.

\section{Procedimiento y análisis de datos}

Para la toma de los datos se optó por revisar los sitios online de cada cadena. El registro de la información obtenida a partir de la hoja de observación lo realizaron dos miembros del estudio, contando con la posterior confirmación de los otros miembros de la investigación. Así, la medición fue llevada a cabo a partir de los post creados por las organizaciones desde el 10 de enero de 2013 hasta 10 de febrero de 2013, y analizados con el programa SPSS 21.0. El análisis llevado a cabo fue descriptivo utilizando para ello sumatorios y medias.

\section{Resultados}

\section{Análisis de la utilización de Facebook}

En la Tabla 1, se puede observar que las páginas que cuentan con el mayor número de Me Gusta son las de CD6 (11723), CD1 (3811), y CD4 (3594). Al compararse este dato con el número de instalaciones, se comprobó que estas tres organizaciones se mantenían en las mismas posiciones, sin embargo apareció entre estos valores CD2 que presentó una media de 727.33 por instalación. Por último la actividad de las organizaciones en Facebook se obtuvo cuantificando el número de post que cada una de ellas realizó en el periodo de análisis. Así se comprobó que CD3, CD6 y CD4 fueron las más activas en esta red social, con un máximo de 36 post.

Tabla 1

\begin{tabular}{|c|c|c|c|c|c|c|c|}
\hline \multirow{2}{*}{ CD } & \multirow[b]{2}{*}{ I } & \multicolumn{3}{|c|}{ Facebook } & \multicolumn{3}{|c|}{ Twitter } \\
\hline & & $M G$ & MG/I & TP & $S$ & $S / I$ & TP \\
\hline CD1 & 11 & 3811 & 346.45 & 29 & 1456 & $\begin{array}{l}132.36 \\
\end{array}$ & 241 \\
\hline $\mathrm{CD} 2$ & 3 & 2182 & 727.33 & 28 & 1099 & 366.33 & 111 \\
\hline $\mathrm{CD} 3$ & 5 & 1551 & 310.2 & 36 & 1368 & 273.6 & 405 \\
\hline $\mathrm{CD} 4$ & 3 & 3594 & 1198 & 30 & 721 & 240.33 & 42 \\
\hline CD5 & 11 & 2997 & 272.45 & 20 & 942 & 85.63 & 103 \\
\hline CD6 & 14 & 11723 & 837.35 & 34 & 4274 & 305.28 & 158 \\
\hline $\mathrm{CD} 7$ & 26 & 2936 & 112.92 & 19 & 1410 & 54.23 & 76 \\
\hline
\end{tabular}

Post en el periodo anal izado; $S=$ Seguidores; $S / I=$ Seguidores/Instalación.

Conocidos los datos de actividad de las organizaciones en Facebook, se clasificaron todos los post según los módulos de contenidos para averiguar cuáles eran los más usados por las compañías. Los resultados obtenidos y plasmados en la Figura 1, mostraron diferentes tendencias. En una visión global se observa que los valores más altos se dieron en los contenidos

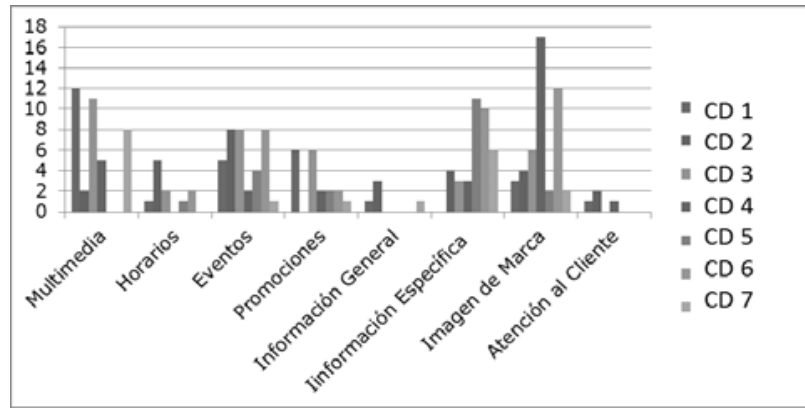

Figura 1. Número total de post en Facebook por módulo de contenidos. multimedia, información específica e imagen de marca, mientras que los de información general, atención al cliente y horarios tuvieron los resultados más bajos.

En el aspecto multimedia, organizaciones como CD5 y CD6 no registraron ningún post, al contrario de CD1 o CD3 que presentaron los registros más altos con 12 y 11 respectivamente. En el módulo de horarios, la cadena que más obtuvo fue CD2 con 5 post, mientras que organizaciones como CD4 o CD7 no realizaron ninguno. Referente a eventos, CD2, CD3 y CD6 mostraron los mismos registros (8) y en promociones CD1 y CD3 fueron los que contaron con mayor actividad con un total de 6 respectivamente. En información general se encontraron los registros más bajos ya que solo 3 organizaciones (CD1, CD2 y CD7) postearon algo sobre este módulo de contenido. Por otro lado en el módulo de información específica, las organizaciones CD5 y CD6 presentaron los números más altos (11 y 10). En el módulo de imagen de marca se registró la mayor actividad por parte de las cadenas CD4 con 17 post, y CD6 con 12. Por último, en el módulo atención al cliente se observó una actividad mínima no superando en ninguna organización el número de 2 posts.

Posterior a estos análisis, tal y como se ilustra en la Tabla 2, se contabilizó el número total de Me Gusta, Comentarios y Compartir de los usuarios por cada uno de los módulos de contenidos. En el apartado Me Gusta, se apreció como los mayores índices de este indicador se encontraban en los contenidos multimedia de CD1 con 339, los contenidos de información específica (250) e imagen de marca (281) de CD6, y los contenidos de imagen de marca de CD4 registrando 539. En lo referente al apartado Compartir, los valores obtenidos en la medición fueron muy bajos, registrándose valores cercanos a 0 en la mayoría de ocasiones. Aun así, algunas organizaciones presentaron valores altos como CD2 en multimedia (27), CD4 en eventos (34), y CD6 en información específica (34) e imagen de marca (37). En el apartado Comentarios, se comprobó que las organizaciones con registros más elevados fueron CD2 y CD1. Concretamente CD2 fue la que recibió mayor número en horarios (48), información general (42) e imagen de marca (45). En esta línea también se encontraba CD1 con 47 en multimedia e imagen de marca, 29 en eventos y 25 en promociones. Por último cabe destacar los valores de CD3 en multimedia (45) y los de CD4 en imagen de marca (36). Justamente, se observó como los módulos de multimedia, horarios, información general e imagen de marca presentaron mayor actividad respecto a otros como información específica o atención al cliente.

Otros de los aspectos considerados fue la valoración de los contenidos, mediante el análisis del número total por módulo de contenido en Me Gusta, Comentarios y Compartir. Los resultados mostraron que los contenidos mejor valorados con Me Gusta fueron la imagen de marca y multimedia con un total de 1338 y 866 respectivamente. En relación a los contenidos Compartir, multimedia (56), información específica (54) e imagen de marca (46) fueron los que mostraron valores más elevados. Por último, entre los contenidos que poseían una media de Comentarios más elevada destaca de igual manera multimedia con 142 e imagen de marca con 143.

\section{Análisis de la utilización de Twitter}

Para la medición de Twitter se utilizaron los mismos análisis que para Facebook. En primer lugar se recopiló el número total de Seguidores por organización, resultando que CD6 fue la que obtuvo mayor número (4274), seguido de CD1 con 1456 y CD7 con 1410. Este dato se relacionó con el número total de instalaciones, donde solo CD6 se mantuvo en los valores más altos con 305.28 Seguidores por instalación. Precisamente CD2 presentó el mayor número con 366.33. Referente al número total de post, se observó en un extremo a CD3 cuyo valor fue de 
Tabla 2

\begin{tabular}{|c|c|c|c|c|c|c|c|c|}
\hline & CD1 & CD2 & CD3 & CD4 & CD5 & CD6 & CD7 & Total \\
\hline \multicolumn{9}{|l|}{ Multimedia } \\
\hline Megusta & 339 & 195 & 203 & 129 & 0 & 0 & 214 & 866 \\
\hline Compartir & 3 & 27 & 5 & 19 & 0 & 0 & 2 & 56 \\
\hline Comentarios & 47 & 23 & 45 & 8 & 0 & 0 & 19 & 142 \\
\hline \multicolumn{9}{|l|}{ Horarios } \\
\hline Me gusta & 17 & 98 & 9 & 0 & 0 & 24 & 0 & 148 \\
\hline Compartir & 0 & 0 & 0 & 0 & 0 & 0 & 0 & 0 \\
\hline $\begin{array}{l}\text { Comentarios } \\
\text { Eventos }\end{array}$ & 5 & 48 & 1 & 0 & 0 & 10 & 0 & 64 \\
\hline Me gusta & 110 & 44 & 25 & 101 & 10 & 94 & 25 & 409 \\
\hline Compartir & 2 & 1 & 1 & 34 & 0 & 0 & 0 & 38 \\
\hline Comentarios & 29 & 16 & 1 & 29 & 2 & 3 & 11 & 91 \\
\hline \multicolumn{9}{|l|}{ Promodiones } \\
\hline Me gusta & 91 & 0 & 108 & 56 & 8 & 30 & 7 & 300 \\
\hline Compartir & 1 & 1 & 0 & 2 & 0 & 1 & 1 & 6 \\
\hline $\begin{array}{l}\text { Comentarios } \\
\text { Información general }\end{array}$ & 25 & 0 & 16 & 16 & 2 & 1 & 0 & 60 \\
\hline Me gusta & 5 & 161 & 0 & 0 & 0 & 0 & 22 & 188 \\
\hline Compartir & 0 & 16 & 0 & 0 & 0 & 0 & 0 & 16 \\
\hline Comentarios & 1 & 42 & 0 & 0 & 0 & 0 & 9 & 52 \\
\hline \multicolumn{9}{|l|}{ Información específica } \\
\hline Me gusta & 0 & 68 & 16 & 77 & 34 & 250 & 66 & 511 \\
\hline Compartir & 0 & 0 & 0 & 17 & 1 & 34 & 2 & 54 \\
\hline $\begin{array}{c}\text { Comentarios } \\
\text { Imagen de marca }\end{array}$ & 0 & 9 & 1 & 7 & 3 & 17 & 8 & 45 \\
\hline Megusta & 194 & 161 & 87 & 539 & 41 & 281 & 35 & 1338 \\
\hline Compartir & 2 & 0 & 0 & 4 & 0 & 37 & 3 & 46 \\
\hline Comentarios & 47 & 45 & 6 & 36 & 0 & 8 & 1 & 143 \\
\hline \multicolumn{9}{|l|}{ Atención al diente } \\
\hline Me gusta & 24 & 28 & 0 & 8 & 0 & 0 & 0 & 60 \\
\hline Compartir & 0 & 0 & 0 & 0 & 0 & 0 & 0 & 0 \\
\hline Comentarios & 1 & 14 & 0 & 5 & 0 & 0 & 0 & 20 \\
\hline
\end{tabular}

405, y en otro a CD4 y CD7 con 42 y 76 respectivamente (Tabla 1).

Conocidos los datos de actividad de las compañías en Twitter, se clasificaron los post por módulo de contenidos y se procedió a analizar los más posteados por las organizaciones. Los resultados mostraron los relacionados con la imagen de marca como los más posteados. Cabe resaltar que CD3 fue la que más utilizó este tipo de contenido, presentando un total de 232, seguido de CD1 con 141 y CD6 con 90 (Figura 2). Por otro lado, el resto de organizaciones presentaron valores por debajo de 40 post en los demás módulos de contenido, siendo información general y horarios los menos posteados.

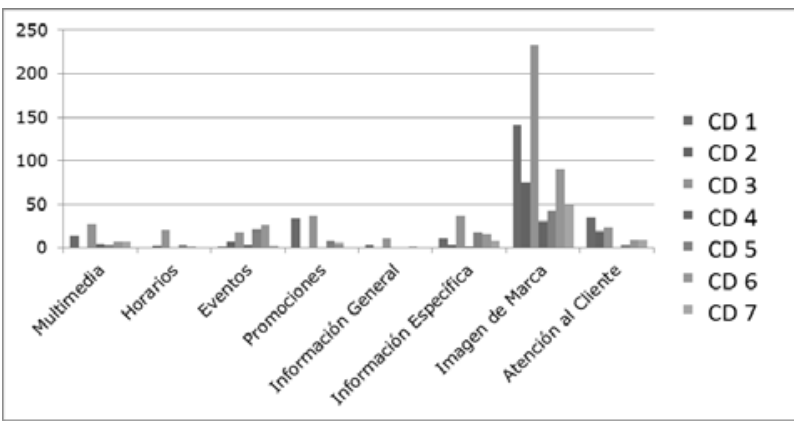

Figura 2. Número total de post en Twitter por módulo de contenido.

Referente a la actividad de los usuarios y su interacción con Twitter, se evaluaron las Menciones, Retweets y Favoritos, contabilizando el número total de estos factores a partir de los módulos de contenido y compañías (Tabla 3). En relación a las Menciones, los valores más altos se hallaron en la imagen de marca. En este sentido, CD1 fue la que obtuvo el mayor valor (85), seguida de CD2 con 30 y CD6 con 23. También cabe destacar los valores positivos en el módulo de atención al cliente en CD1 (35), CD2 (21) y CD3 (19). Referente a los Retweet, los valores más altos se situaron en imagen de marca en las organizaciones CD2 (109), CD6 (87) y CD3 (55), aunque destacaron los 141 de CD3 en información específica. Por otro lado en Favoritos, el módulo de información específica fue el que obtuvo el valor mayor (84) en la organización CD3, y en imagen de marca en CD2 (45) y CD6 (20). Finalmente se obtuvo el número total de Menciones, Retweets y Favoritos por módulo de contenido, resultando con mayores valores imagen de marca en Menciones (152) y Retweet (309), y 101 Favoritos en el módulo de información específica.
Tabla 3

\begin{tabular}{|c|c|c|c|c|c|c|c|c|}
\hline & CD1 & CD2 & CD3 & CD4 & CD5 & CD6 & CD7 & Total \\
\hline \multicolumn{9}{|l|}{ Multimedia } \\
\hline Menciones & 3 & 0 & 1 & 2 & 0 & 3 & 0 & 9 \\
\hline Retweets & 6 & 0 & 19 & 3 & 0 & 9 & 7 & 44 \\
\hline Favoritos & 1 & 0 & 15 & 1 & 0 & 5 & 1 & 23 \\
\hline \multicolumn{9}{|l|}{ Horarios } \\
\hline Menciones & 0 & 1 & 0 & 0 & 0 & 0 & 0 & 1 \\
\hline Retweets & 0 & 3 & 4 & 0 & 0 & 0 & 0 & 7 \\
\hline \multirow{2}{*}{\multicolumn{9}{|c|}{ Eventos }} \\
\hline & & & & & & & & \\
\hline Menciones & 1 & 0 & 0 & 0 & 6 & 3 & 0 & 10 \\
\hline Retweets & 1 & 30 & 7 & 0 & 30 & 2 & 11 & 81 \\
\hline Favoritos & 0 & 3 & 1 & 0 & 3 & 1 & 3 & 11 \\
\hline \multicolumn{9}{|l|}{ Promociones } \\
\hline Menciones & 12 & 0 & 5 & 0 & 0 & 0 & 0 & 17 \\
\hline Retweets & 20 & 6 & 15 & 0 & 1 & 1 & 0 & 43 \\
\hline Favoritos & 1 & 2 & 13 & 0 & 2 & 1 & 0 & 19 \\
\hline \multicolumn{9}{|c|}{ Información General } \\
\hline Menciones & 0 & 1 & 0 & 0 & 0 & 0 & 0 & 1 \\
\hline Retweets & 8 & 2 & 2 & 0 & 6 & 0 & 0 & 18 \\
\hline Favoritos & 2 & 1 & 0 & 0 & 0 & 0 & 0 & 3 \\
\hline \multicolumn{9}{|c|}{ Información Específica } \\
\hline Menciones & & 1 & 7 & 0 & 2 & 2 & 1 & 13 \\
\hline Retweets & 1 & 7 & 141 & 1 & 29 & 12 & 20 & 211 \\
\hline Favoritos & 1 & 1 & 84 & 0 & 3 & 6 & 6 & 101 \\
\hline \multicolumn{9}{|c|}{ Imagen de Marca } \\
\hline Menciones & 85 & 30 & 7 & 2 & 0 & 23 & 5 & 152 \\
\hline Retweets & 13 & 109 & 55 & 24 & 11 & 87 & 10 & 309 \\
\hline Favoritos & 3 & 45 & 9 & 2 & 7 & 20 & 1 & 87 \\
\hline \multicolumn{9}{|c|}{ Atención al Cliente } \\
\hline Menciones & 35 & 21 & 19 & 0 & 0 & 3 & 6 & 84 \\
\hline Retweets & 0 & 5 & 0 & 0 & 0 & 0 & 0 & 5 \\
\hline Favoritos & 0 & 0 & 0 & 0 & 0 & 0 & 2 & 2 \\
\hline
\end{tabular}

\section{Discusión}

La experiencia positiva de los usuarios en las redes sociales de las diferentes organizaciones puede incrementar la notoriedad de la marca, incrementar el tráfico en la web, vender productos o servicios y generar contactos con clientes potenciales (ADIGITAL, 2014), e incluso incentivar a otras personas a que las recomienden en base a su experiencia (He et al., 2013). Por esta razón, cobra gran importancia el correcto uso de las redes sociales, puesto que se están convirtiendo en una nueva forma de interactuar con los usuarios a través de las cuales las empresas de servicios deportivos promocionan sus marcas mediante el intercambio de contenido o la colocación de información en sus espacios públicos (Hambrick, Frederick \& Sanderson., 2013; Pronschinske et al., 2012).

Los resultados obtenidos muestran diferentes niveles de actividad por parte de las cadenas de centros de fitness de España, estando algunas más comprometidas y concienciadas sobre la importancia del cuidado y seguimiento del cliente a partir de las nuevas tecnologías. En primer lugar, si se compara la actividad en Facebook y en Twitter, claramente favorece a la primera red social puesto que cuenta con más usuarios tal y como ya ponían de manifiesto algunas organizaciones (Observatorio Nacional de Telecomunicaciones y de la SI, 2011). Todo esto a pesar de que Twitter tiene mayor actividad de post en el periodo de medición que Facebook. Las explicaciones sobre la elevada actividad en Twitter se pueden encontrar en diferentes aspectos. Por una parte McEnnis (2013) descubrió que los periodistas hacían comentarios más veraces en Twitter que en los medios de comunicación tradicionales como la prensa escrita, la radio o la televisión. Otra razón puede ser la propia naturaleza de la red social ya que Twitter favorece a través de su sistema de menciones que los usuarios interactúen entre ellos. Igualmente, también podría deberse al alto número de post del tipo atención al cliente donde se establecen conversaciones entre los usuarios. Justamente, el número de Me Gusta en Facebook y de Seguidores en Twitter es importante de cara a poder difundir los contenidos entre los contactos que están conectados a los usuarios de las organizaciones. La dinámica consiste en que cada vez que un usuario pulsa Me Gusta en una página de Facebook, esto se publica en su muro en Facebook. De una manera parecida ocurre en Twitter, ya que al seguir a un perfil hace que la propia red la recomiende a los Seguidores del usuario. Facebook por su parte también presenta sus propias ventajas entre las que se encuentran que la interacción con los fans y los debates en 
Facebook puede repercutir favorablemente en el número de fans de un marca deportiva (Pronschinske et al., 2012).

En lo que se refiere a tipología de contenido, todas las cadenas coinciden en utilizar en Twitter los mismos módulos de contenido (imagen de marca y atención al cliente), mientras que en Facebook cada una de las organizaciones crea post en función a los objetivos de cada una de ellas. Por ejemplo en el caso de CD6, al estar centrada en el cuidado de la salud, utiliza en gran medida los contenidos de información específica para proponer a sus usuarios prácticas saludables. Otro ejemplo es el de CD3 y CD1 que utilizan el módulo multimedia a partir del cual suben periódicamente fotografías de sus clases colectivas.

Por otro lado, el proceso de medición en Facebook aclaró formas de utilizar esta herramienta y patrones que se repetían en muchos casos en las diferentes páginas de las organizaciones. Una de las prácticas más utilizadas fue postear información en imágenes, utilizando un gran componente visual como medio de atraer la atención de los usuarios. Esta tendencia por el uso de imágenes supondría grandes valores en la medición del módulo de contenido multimedia. Sin embargo a la hora de medir los contenidos este estudio se ha centrado en la naturaleza del mensaje que se quiere transmitir independientemente del formato en el que aparece, evitando un excesivo descuadre de los resultados. Concretamente, durante las mediciones se fueron leyendo gran cantidad de mensajes y analizando numerosas interacciones entre empresa y cliente. Así, en la mayoría de las ocasiones estas interacciones eran en forma de pregunta acerca de alguno de los servicios de la organización, en forma de petición o sugerencia e incluso de apoyo y felicitaciones por el buen funcionamiento de la misma.

En lo que concierne al módulo atención al cliente, la mayoría de mensajes se reflejaban en la plataforma Twitter, ya que la propia naturaleza de esta red favorece las conversaciones directas entre un usuario y la organización. Este medio permitió conocer de primera mano todas las opiniones, dudas, sugerencias o quejas que lo clientes podrían tener respecto a la organización, ampliando la capacidad de respuesta ante problemas con los usuarios e incrementando la posibilidad de mejorar la relación con estos. Es por ello que tal y como proponían Williams y Chinn (2010), este mecanismo ayudaría a mejorar la satisfacción del cliente en este tipo de organización deportiva.

Referente a la opinión de los usuarios sobre los contenidos que postean las organizaciones y teniendo en cuenta los resultados, se pueden destacar los siguientes aspectos. En Facebook los contenidos que más se aceptan por parte de los usuarios son los relacionados con imagen de marca y multimedia. Los de primer tipo tienen gran acogida por su alto componente de positividad, humor y energía positiva, es decir, son contenidos alegres que motivan a los usuarios por lo que son los más comentados y compartidos. Por otro lado en el ámbito multimedia, la mayoría de las fotografías o videos son creados por los propios usuarios durante sus entrenamientos en la instalación. Esto suscita gran interés, ya que los clientes se sienten los protagonistas de la organización.

Para finalizar, el módulo de contenido en Twitter con mayor repercusión fue imagen de marca, puesto que la mayoría de ellos son utilizados por las organizaciones de forma diaria para dinamizar y establecer conversaciones con los usuarios. Así, en lo referente a las medias de los Retweets, destaca el módulo información específica ya que cuenta con mayor difusión, debiéndose seguramente a que este tipo de contenido engloba consejos saludables o tablas de ejercicios, lo que hace de gran utilidad no solo para los clientes si no para el resto de usuarios.

\section{Limitaciones y futuras líneas de investigación}

Aunque creemos que esta investigación es pionera en el estudio de las redes sociales en la industria del fitness, y por lo tanto necesaria para la mejora de la gestión en los centros de fitness, no está exenta de limitaciones. La primera está orientada al tiempo de recogida de datos ya que se recogió información durante un mes tal y como lo hicieron He et al. (2013). De igual modo, creemos que haber analizado dos redes sociales de todas las actuales se podría entender como una limitación, pero también es cierto que estas fueron las dos redes sociales que más utilizaron estas organizaciones deportivas. Por otra parte, la novedad del estudio y por lo tanto la ausencia de investigaciones que analicen el uso de estas nuevas formas de comunicarse con los clientes, hace que exista una falta de literatura, que sin duda, se entiende como limitación de la investigación.

No obstante, estas limitaciones son canales para futuras investigaciones. En este sentido, los próximos estudios podrían ir encaminados hacia el análisis de periodos más duraderos ya que sin duda, ofrecerían más datos de utilización y de interacción de las redes sociales. Igualmente, existen centros de fitness que ya utilizan otras redes tales como YouTube o LinkedIn que se postulan también para analizar. Asimismo, analizar la relación entre el número de seguidores con el número de aportaciones se demanda como futura línea de investigación. Su estudio y su repercusión en la gestión, se posiciona como una investigación novedosa y futura.

\section{Conclusiones}

Debido a los hallazgos encontrados en la utilización de las redes sociales en las cadenas de centros de fitness, este estudio presenta las siguientes conclusiones que pretenden ser motivo de reflexión para los gerentes de estas organizaciones. El uso de las redes sociales en cada cadena de centros de fitness es muy diferente. En las dos redes sociales, imagen de marca e información específica fueron los módulos de contenido con más tweets y posts. En Facebook, el módulo de contenido menos posteado fue atención al cliente, mientras que en Twitter fueron horarios e información general. En cuanto a la naturaleza de los comentarios en Facebook los Me Gusta fueron los más posteados y Compartir los que menos. En Twitter los Retweets fueron los más numerosos, observándose cierta igualdad entre Favoritos y Menciones.

\section{Implicaciones prácticas}

El mercado del fitness es una industria en crecimiento donde tal y como se ha comentado, España está posicionada como uno de los países con mayor facturación y número de clientes. Por ello las conclusiones de este trabajo podrían servir tanto a las demás cadenas como a las localizadas en otros países.

Los resultados han mostrado que existen diferentes tipos de utilización de las redes sociales en cadenas de centros de fitness, existiendo también diferencias en el número de fans y de seguidores. Precisamente, las redes sociales tienen la capacidad de interactuar con los clientes y este aspecto es crucial hoy en día, para conocer de primera mano, qué opina el cliente. Así, los hallazgos encontrados ponen de manifiesto que los contenidos a potenciar los gestores de las redes sociales en este sector deportivo en general, son principalmente los que estén asociados a la creación de un ambiente positivo en torno a la imagen de la organización tales como mensajes de bienvenida, motivadores o de agradecimientos. Igualmente, deberán fomentar contenidos relacionados con el cuidado de la salud, programas de entrenamiento o incluso la comunicación de eventos deportivos. En concreto, Facebook deberá ser un instrumento de interacción mediante fotos o imágenes, y Twitter, como medio para informar a los clientes de novedades o información de repercusión inmediata. 
En resumen, los contenidos que planteen los gestores de redes sociales corresponderán a potenciar la atracción, los comentarios y la divulgación de los mismos para por un lado incrementar la interacción con los clientes, y por otro, aumentar la visibilidad de la organización deportiva.

\section{Referencias}

Abreza, G., O’Reilly, N., \& Reid, I. (2013). Relationship marketing and social media in sport. International Journal of Sport Communication, 6, 120-142.

Afthinos, Y., Theodorakis, N., \& Nassis, P. (2005). Customers' expectations of service in Greek fitness centers: Gender, age, type of sport center, and motivation differences. Managing Service Quality, 15(3), 245-258.

Aggarwal, R., Gopal, R., Sankaranarayanan, R., \& Singh, P. V. (2012). Blog, blogger, and the ûrm: Can negative employee posts lead to positive outcomes? Information Systems Research, 23(2), 306-322.

Aguado, G., \& García A. (2009). Del «Word-of-mouth» al marketing viral: aspectos claves de la comunicación a través de redes sociales. Comunicación y Hombre: Revista Interdisciplinar de Ciencias de la Comunicación y Humanidades, 5, 41-51.

Asociación Española de la Economía Digital, ADIGITAL (2014). Informe sobre uso de redes sociales en empresas. Recuperado de https://www.adigital.org/?noticias=mas-de-la-mitad-de-lasempresas-afirman-que-el-retorno-en-redes-sociales-es-igual-o

Asociación para la Investigación en Medios de Comunicación, AIMC (2014). Audiencia de Internet. Recuperado de file:/// D:/Mis\%20documentos/Downloads/internet314.pdf

Australian Bureau of Statistics, ABS (2011). Household use of information technology, Australia, 2010-11. Recuperado de http://www.abs.gov.au/ausstats/abs@.nsf/Latestproducts/ ACF271EB9B03C086CA25796600152C94?opendocument

Brodie, R., Hollebeek, L., Juric', B., \& Ilic', A. (2011). Customer engagement conceptual domain, fundamental propositions, and implications for research. Journal of Service Research, 14, 252-271.

Brodie, R., Ilic', A., Juric', B., \& Hollebeek, L. (2013). Consumer engagement in a virtual brand community: An exploratory analysis. Journal of Business Research, 66, 105-114.

Chang, Y., \& Jay, M. (2012). The influence of multiple types of service convenience on behavioral intentions: The mediating role of consumer satisfaction in a Taiwanese leisure setting. International Journal of Hospitality Management, 31, 107 118.

Coyle, P. (2010). Teams active in social media build strategic advantage. Street \& Smith's SportsBusiness Journal, 12, 18.

Datamonitor (2010). Leisure Facilities Industry Profile. London: Datamonitor Europe.

European Commission (2014). Special Eurobarometer 412. Sport and Physical Activity. Bruselas: European Commission.

Filo, K., Lock, D., \& Karg, A. (en prensa). Sport and social media research: A review. Sport Management Review.

Gantz, W. (2013). Reûections on communication and sport: On fanship and social relationships. Communication \& Sport, 1, 167-187.

García Ferrando, M., \& Llopis, R. (2011). Ideal democrático y bienestar personal. Encuesta sobre los hábitos deportivos en España 2010. Madrid: Consejo Superior de Deportes.

García, J., \& Pires, F. (2010). Fidelización de usuarios mayors en centros de fitness: gestión de clientes por programas de actividad física. Retos, Nuevas Tendencias en Educación Física, Deporte y Recreación, 17, 103-106.

García, J., Cepeda, G., \& Martín, D. (2012). La satisfacción de clientes y su relación con la percepción de calidad en centros de fitness: utilización de la escala CALIDFIT. Revista de Psicología del Deporte, 21(2), 309-319.

García, J., Lera-López, F., \& Suárez, M. (2011). Estimation of a structural model of the determinants of the time spent on physical activity and sport: Evidence for Spain. Journal of Sports Economics, 12(5), 515-537.

García-Fernández, J., Bernal-García, A., Fernández-Gavira, J., \& Vélez-Colón, L. (2014). Analysis of existing literature on management and marketing of the fitness centre industry. South African Journal for Research in Sport, Physical Education and Recreation, 36(3), 75-91.

Guedes, P., Maças, P., \& Serrasqueiro, Z. (2013). Growth determinants of small- and medium-sized fitness enterprises: empirical evidence from Portugal. European Sport Management Quarterly, 13(4), 428-449.

Hambrick, M. E., Frederick, E. L., \& Sanderson, J. (2013). From yellow to blue: Exploring Lance Armstrong's image repair strategies across traditional and social media. Communication \& Sport. 4, 1-23.

He, W., Zha, S., \& Li, L. (2013). Social media competitive analysis and text mining: A case study in the pizza industry. International Journal of Information Management, 3(3), 464-472.

Hopkins, J. L. (2013). Engaging Australian Rules Football fans with social media: A case study. International Journal of Sport Management and Marketing, 13, 104-121

International Health, Racquet \& Sportsclub Association (2012). The IHRSA Global Report 2011. Boston: IHRSA.

Martínez, J. A., \& Martínez, L. (2010). La medición de la satisfacción del consumidor de servicios deportivos a través de la lógica borrosa. Revista de Psicología del Deporte, 19(1), 4148

McEnnis, S. (2013). Raising our game: Effects of citizen journalism on Twitter for professional identity and working practices of British sport journalists. International Journal of Sport Communication, 6, 423-433.

Morales, V., Hernández-Mendo, A., \& Blanco, A. (2009). Evaluación de la calidad en organizaciones deportivas: adaptación del modelo SERVQUAL. Revista de Psicología del Deporte, 18(2), 137-150.

Nuviala, A., Pérez-Ordás, R., Boceta, M., Grao-Cruces, A., Nuviala, R., \& González, J. A. (2012). Calidad, satisfacción y valor percibido de los usuarios de un servicio deportivo público. Movimento, 18(4), 11-32.

Observatorio Nacional de Telecomunicaciones y de la SI (2011) Las redes sociales en internet. Recuperado de http:// www.ontsi.red.es/ontsi/sites/default/files/redes_socialesdocumento_0.pdf

Özsoy, S. (2011). Use of New Media by Turkish Fans in Sport Communication: Facebook and Twitter. Journal of Human Kinetics, 28, 165-176.

Pedersen, P. M. (2013). Reûections on communication and sport: On strategic communication and management. Communication \& Sport, 1, 55-67.

Pew Research Center (2013). Social media update 2013. Recuperado de http://pewinternet.org/_/media//Files/Reports/2013/ Social\%20Networking\%202013_PDF.pdf

Pronschinske, M., Groza, M., \& Walker, M. (2012). Attracting Facebook 'fans': The importance of authenticity and engagement as a social networking strategy for professional sport teams. Sport Marketing Quarterly, 21, 221-231.

Rial, A., Alonso, D., Rial, J., Picón, E., \& Varela, J. (2009). Un intento de segmentación integral de los usuarios de centros deportivos. Apunts, Educación Fisica y Deportes, 95, 82-91.

Sacavém, A., \& Correia, A. (2009). The industry of wellness: the improvement of well-being. International Journal of Sport Management and Marketing, 5(4), 417-425.

Williams, J., \& Chinn, S. (2010). Meeting relationship-marketing goals through social media: A conceptual model for sport marketers. International Journal of Sport Communication, 3, 422-437.

Yoshida, M., Gordon, B., Nakazawa, M., \& Biscaia, R. (2014). Conceptualization and measurement of fan engagement: Empirical evidence from a professional sport context. Journal of Sport Management, 28, 399-417. 